\title{
Program Hypnomathematics melalui Kata-Kata Positif untuk Guru SD 2 Bae, Kudus
}

\author{
Savitri Wanabuliandari ${ }^{1}$, Ristiyani ${ }^{2}$ \\ 1, 2 Universitas Muria Kudus
}

\begin{tabular}{|c|c|}
\hline Article History & ABSTRACT \\
\hline $\begin{array}{l}\text { Received } 12.04 .2019 \\
\text { Received in revised form } \\
28.07 .2019 \\
\text { Accepted } 08.10 .2019 \\
\text { Available online } 28.10 .2019\end{array}$ & $\begin{array}{l}\text { TRAINING OF HYPNOMATHEMATICS THROUGH POSITIVE WORDS FOR } \\
\text { TEACHERS AT SD } 4 \text { BAE. Mathematics is known as a subject that plays an } \\
\text { important role in the world of education. Mathematics is also a basic knowledge } \\
\text { that students must have in order to be able to continue to a higher level. } \\
\text { Mathematics in elementary school is known as a subject that many students don't } \\
\text { like and fear because it is considered difficult. The emergence of fear and difficult } \\
\text { assumptions in mathematics due to the lack of students are motivated to learn } \\
\text { Mathematics. From the results of the observations, it was found that teachers } \\
\text { tended to be less attentive to students who were not active in mathematics, } \\
\text { teachers also did not respond well when students had difficulty learning } \\
\text { mathematics, teachers used negative words and were more inclined to frighten } \\
\text { students who experienced difficulties in learning mathematics, and the teacher } \\
\text { does not give a positive response to student success. Based on these problems, the } \\
\text { purpose of these service is to provide training in hypnomathematics through } \\
\text { positive words. Provide training in hypnomathematics through positive words } \\
\text { that are able to improve teacher skills in motivating students to learn } \\
\text { mathematics.The target of this service is to provide knowledge and training to } \\
\text { teachers at SD } 4 \text { Bae about using hypnomathematics through positive words to } \\
\text { motivate students.The method used in this service is interactive training and } \\
\text { mentoring. As a result of this service, SD } 4 \text { Bae teachers were able to improve their } \\
\text { skills in motivating student learning during mathematics learning. }\end{array}$ \\
\hline & KEYWORDS: Hypnomathematics, Positive Words, Teachers. \\
\hline
\end{tabular}
Attribution 4.0 International License, which permits unrestricted use, distribution, and reproduction in any medium, provided the original work is properly cited. (c) 2019 Savitri Wanabuliandari, Ristiyani.

\section{PENDAHULUAN}

Matematika dikenal sebagai mata pelajaran yang memegang peranan penting di dunia pendidikan. Matematika juga merupakan pengetahuan dasar yang wajib dimiliki siswa agar dapat lanjut ke jenjang yang lebih tinggi. Matematika di sekolah dasar dikenal sebagai mata pelajaran yang tidak disukai serta ditakuti banyak siswa karena dianggap

${ }^{1}$ Corresponding author: Program Pendidikan Matematika, FKIP Universitas Muria Kudus; PO BOX 53 Bae 59324 Kudus, Jawa Tengah, Indonesia; Email: savitri.wanabuliandari@umk.ac.id 
sulit. Munculnya rasa takut dan anggapan sulit pada matematika dikarenakan kurangnya siswa mendapat motivasi belajar Matematika. Motivasi belajar adalah keseluruhan daya penggerak dalam diri siswa yang menimbulkan kegiatan belajar, yang menjamin kelangsungan dari kegiatan belajar dan memberikan arah pada kegiatan belajar, sehingga tujuan yang dikehendaki oleh subyek belajar itu dapat tercapai (Sardiman, 1986: 75). Hal ini lah yang menyebabkan menurunnya motivasi belajar matematika pada siswa.

Motivasi adalah alasan seseorang dalam berperilaku pada suatu keadaan tertentu. Motivasi dapat menyebabkan perubahan perasaan dan emosi dalam melakukan sesuatu. Motivasi dalam belajar matematika pada siswa umumnya masih rendah. Kuat lemahnya motivasi siswa dalam belajar matematika akan berpengaruh terhadap prestasi belajarnya. Penciptaan suasana belajar yang positif dapat mempengaruhi motivasi siswa dalam belajar matematika. Salah satu yang memegang peranan penting dala penciptaan suasana belajar siswa adalah guru.

Guru merupakan sosok yang selalu mejadi tolak ukur dalam keberhasilan pembelajaran. Guru selalu dituntut untuk bertindak profesional. Guru juga dituntut untuk selalu mengembangkan kualitas dirinya. Guru juga dituntut untuk selalu membimbing dan mengarahkan siswanya agar menjadi lebih baik. Guru sebagai pendidik juga berperan sebagai motivator yang memdorong siswa dalam kegiatan pembelajaran. Akan tetapi dalam pelaksanaannya guru masih kurang maksimal dalam memotivasi siswa untuk belajar matematika. Hal ini nampak dari hasil observasi awal yang telah dilakukan. Berdasarkan hasil observasi di SD 4 Bae, ditemukan bahwa guru cenderung kurang perhatian terhadap siswa yang tidak aktif dalam pelajaran matematika sehingga mengakibatkan siswa tidak malas mengikuti pembelajaran. Guru juga tidak merespon dengan baik ketika siswa mengalami kesulitan saat belajar matematika sehingga siswa semakin tidak tertarik dalam pembelajaran. Guru menggunakan kata-kata negatif serta lebih condong menakut-nakuti siswa yang mengalami kesulitan dalam belajar matematika sehingga siswa cenderung takut untuk bertanya ketika mengalami kesulitan belajar. Selain itu, guru juga tidak memberikan respon positif terhadap keberhasilan siswa sehingga siswa merasa kurang dihargai. Berdasarkan hasil wawancara dengan siswa menunjukkan hasil bahwa siswa merasa matematika sulit dan matematika merupakan mata pelajaran yang mengerikan. Siswa juga berpendapat bahwa selama ini guru jarang memberikan motivasi belajar, guru juga cenderung kurang perhatian terhadap siswa yang kurang pintar, guru jarang memberikan pujian dan lebih sering menakut-nakuti bahwa matematika sulit. Hal ini berarti guru harus mulai mengajak siswa untuk selalu berpikir positif agar anggapan bahwa matematika sulit dan menakutkan dapat segera diatasi.

Dalam belajar matematika siswa harus selalu berpikiran positif. Pikiran yang positif dapat memperkuat kepribadian seseorang. Pikiran positif akan memacu siswa untuk selalu berusaha memaksimalkan potensi dirinya. Berpikir positif membuat siswa semakin termotivasi dalam belajar terutama saat pembelajaran matematika. Salah satu kelebihan dari berpikir positif yaitu mempunyai pengaruh dalam melakukan sesuatu dengan tepat. Berpikir positif menjadi bekal siswa untuk dapat belajar matematika dengan baik. Melalui berpikir positif siswa tidak akan takut dan tidak mudah menyerah. Keuntungan lain dari berpikir positif adalah dapat mengarahkan siswa untuk fokus terhadap kelebihan yang dimiliki sehingga siswa merasa bangga terhadap diri mereka sendiri. Keuntungan berpikir positf ini akan menjadikan siswa lebih optimis dan lebih percaya diri. 
Salah satu cara agar siswa dapat berpikir postif adalah dengan menerapkan hypnomathematic. Hypnomathematics adalah akronim dari Hypnoteaching dan Matematika. Menurut Wati dan Kusuma (2016) hypnoteaching merupakan bentuk sikap guru untuk menyugesti siswa dengan tujuan memberi pembelajaran yang baik. Jadi Hpynomathematics merupakan cara guru untuk menyugesti siswa agar siswa dapat belajar matematika dengan baik. Hypnomatemathics yang dapat diterapkan adalah melalui positive word. Kata positif yang diucapkan oleh guru memberikan pengaruh yang besar dalam kegiatan pmbelajaran. Tanudjaja (2007) menyebutkan bahwa kata-kata positif dapat membangun hubungan dengan siswa melalui perasaan. Kata positif dapat membangun kepercayaan diri siswa sehingga terjadi perubahan tingkah laku yang lebih positif.

Berdasarkan analisis situasi tersebut, penting kiranya diajukan kegiatan pengabdian kepada masyarakat sebagai salah satu upaya untuk menggerakkan, mengarahkan, memberikan Ipteks bagi Masyarakat yang dapat mendorong guru untuk terampil dalam menyugesti siswa melalui kata-kata positif dengan hypnomathematics. Ipteks bagi Masyarakat ini dapat diaplikasikan sehingga pemanfaatannya sangat berguna bagi sekolah, masyarakat sekitar dan perkembangan ilmu pengetahuan.

Tujuan dari pelatihan hypnomathematics melalui kata-kata positif untuk guru di SD 4 Bae adalah sebagai berikut: (1) memberikan pelatihan hypnomathematics melalui katakata positif, dan (2) memberikan pelatihan hypnomathematics melalui kata-kata positif yang mampu meningkatkan keterampilan guru dalam memotivasi siswa untuk belajar matematika.

\section{METODE PELAKSANAAN}

Dalam kegiatan pengabdian ini mitra berasal dari SD 4 Bae di Kecamatan Bae Kabupaten Kudus. SDN 4 Bae mewakili populasi yang ada di Kecamatan Bae, hampir semua sekolah yang ada di kecamatan Bae memiliki permasalahan dalam meningkatkan motivasi belajar siswa saat mata pelajaran matematika. Selain itu, Dari hasil observasi didapatkan hasil bahwa guru cenderung kurang perhatian terhadap siswa yang tidak aktif dalam pelajaran matematika, guru juga tidak merespon dengan baik ketika siswa mengalami kesulitan saat belajar matematika, guru menggunakan kata-kata negatif serta lebih condong menakut-nakuti siswa yang mengalami kesulitan dalam belajar matematika, dan guru tidak memberikan respon positif terhadap keberhasilan siswa.

Kegiatan pengabdian kepada masyarakat yang berbentuk pelatihan hypnomathematics melalui Kata-Kata Positif. Adapun jumlah guru yang ikut dalam pelatihan dan pendampingan sebanyak 10 orang guru kelas dan 1 kepala sekolah. Adapun fasilitator pendampingan ini adalah Ristiyani, S. Pd, M. Pd dari Program Studi Pendidikan Bahasa dan Sastra Indonesia FKIP Universitas Muria Kudus dan Savitri Wanabuliandari, S.Pd, M.Pd dari Program Studi Pendidikan Matematika FKIP Universitas Muria Kudus. Pengabdian ini juga melibatkan dua mahasiswa.

Metode yang digunakan dalam pengabdian ini adalah dengan menggunakan pendekatan participant active learning. Bentuknya adalah pelatihan interaktif. Adapun tahapan metode yang digunakan dalam proses pelatihan dan pendampingan ini menggunakan: 1) Ceramah; 2) Tanya Jawab; 3) Diskusi; 4) Curah Pendapat; dan 5) Praktik. Pertama menggunaka metode ceramah yang digunakan untuk menyampaikan materi 
pelatihan, seperti: permasalahan belajar pada mata pelajaran matematika, dan hypnomathematics melalui kata-kata positif. Setelah itu, metode tanya jawab yang digunakan untuk penyampaian materi pelatihan yang dilakukan dengan tujuan memberikan kejelasan suatu informasi/ pengetahuan dan konsep dengan cara mengajukan pertanyaan dan dijawab oleh pihak lain. Dilanjutkan dengan diskusi yang dilakukan dengan melibatkan peserta pelatihan dalam membahas dan memecahkan permasalahan yang ditugaskan dalam kegiatan pelatihan sehingga ada kegiatan saling bertukar pikiran terkait ide dan gagasan masing-masing untuk kemudian melahirkan kesepakatan bersama. Setelah Diskusi kemudian dilanjutkan dengan curah pendapat untuk mengetahui pendapat peserta pelatihan dan pendampingan terhadap suatu permasalahan. Jika permasalahan dapat dirumuskan, tahap selanjutnya digunakan studi kasus untuk membahas suatu kasus/permasalahan yang spesifik dan diperlukan pemecahannya. Terakhir peserta difasilitasi untuk praktik dalam pelatihan hypnomathematics melalui kata-kata positif dengan arahan fasilitator.

\section{HASIL DAN PEMBAHASAN}

Hasil yang dicapai dalam kegiatan ini, secara garis besar terdiri atas: 1) pra kegiatan, 2) tahap perencanaan kegiatan, 3) tahap pelaksanaan kegiatan pelatihan, 4) tahap follow up kegiatan pelatihan dalam bentuk praktek pelatihan hypnomathematics melalui katakata positif, dan 5) tahap evaluasi kegiatan. Pertama, tahap pra kegiatan; Pada tahap ini tim pengabdian melakukan kegiatan perijinan ke sekolah mitra sesuai dengan $\mathrm{MoU}$ yang pernah disepakati bersama.

Kedua, tahap perencanaan kegiatan; Pada tahap perencanaan tim pengabdian membuat rencana dan rancangan dengan melakukan kegiatan: a) Studi lapangan dan analisis kebutuhan berdasarkan fakta lapangan guna menentukan rancangan desain kegiatan pembelajaran; b) Pengumpulan sumber rujukan dan studi literatur tentang hypnomathematics melalui kata-kata positif; c) Perencanaan Ipteks (materi pelatihan) yang akan ditransfer kepada guru SDN 4 Bae. Rancangan materi pelatihan ini terdiri dari: permasalahan belajar pada mata pelajaran matematika, dan hypnomathematics melalui kata-kata positif. Ketiga, tahap pelaksanaan; Pada tahap pelaksanaan, tim pengabdian memberikan pelatihan dan pendampingan dalam bentuk kegiatan (Gambar 1): a) Sosialisasi pelatihan hypnomathematics melalui kata-kata positif; b) Pemaparan materi permasalahan belajar pada mata pelajaran matematika; dan c) Pemaparan materi tentang hypnomathematics melalui kata-kata positif.
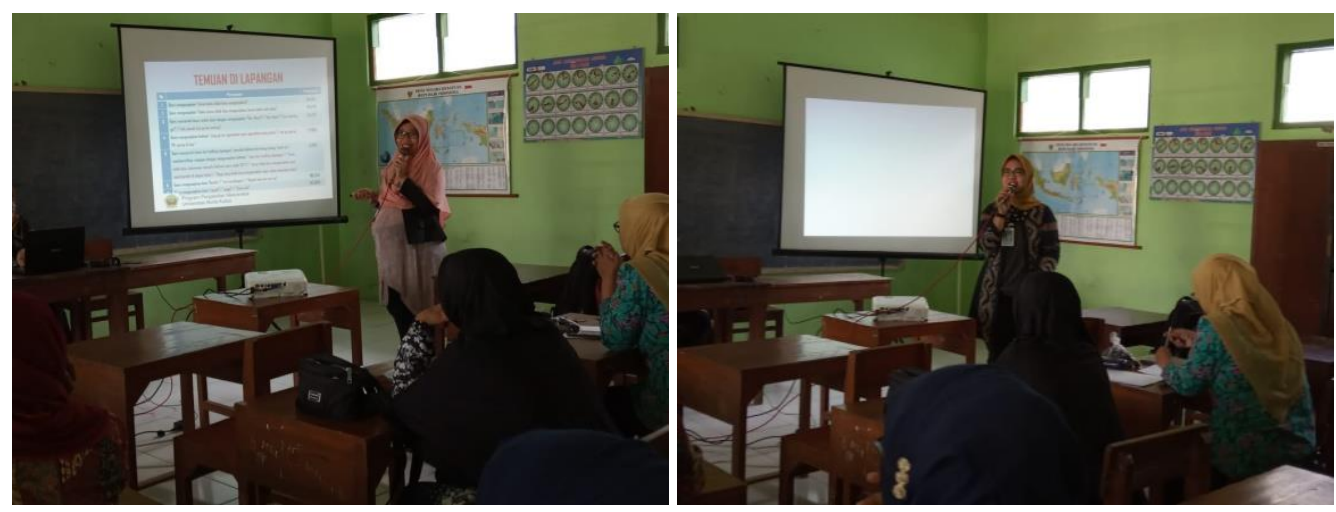

Gambar 1. Pelaksanaan Kegiatan Pelatihan Hypnomathematics Melalui Kata-Kata Positif 
Keempat, Tahap follow up kegiatan pelatihan dilakukan dalam bentuk praktik penggunaan hypnomathematics melalui kata-kata positif. Produk hasil pelatihan berupa keterampilan guru dalam menggunakan hypnomathematics melalui kata-kata positif.
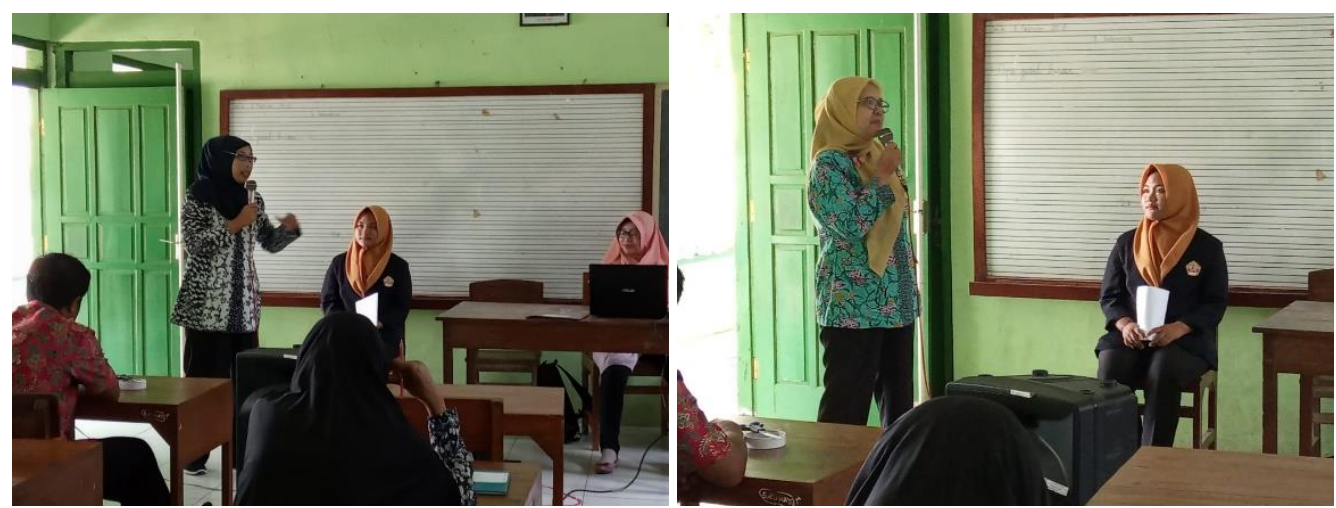

Gambar 2. Praktik Kegiatan Pelatihan Hypnomathematics Melalui Kata-Kata Positif

Kelima, tahap evaluasi yang dilaksanakan pada dua langkah: 1) Evaluasi oleh teman sejawat peserta pelatihan. Kegiatan evaluasi ini dilakukan oleh teman sejawat berupa kegiatan saling menilai, memberi saran dan penghargaan atas hasil karya produk peserta pelatihan serta kegiatan hypnomathematics melalui kata-kata positif. Tujuan dari kegiatan ini adalah untuk mengumpulkan masukan dari teman sejawat untuk seluruh kegiatan dari pelatihan hypnomathematics melalui kata-kata positif. 2) Evaluasi hasil pelatihan dan pendampingan oleh tim pengabdian. Tim pengabdian melakukan kegiatan evaluasi, menilai, memberi saran, masukan dan penghargaan terkait hasil pelatihan, dan kegiatan praktik hypnomathematics melalui kata-kata positif yang dilakukan dan dibuat oleh peserta pengabdian.

Dari hasil evaluasi, diperoleh bahwa kegiatan pelatihan hypnomathematics melalui kata-kata positif, berjalan dengan lancar, aktif, kreatif, efektif dan menyenangkan. Guruguru SD 4 Bae memperoleh: 1) Pengetahuan tentang hypnomathematics melalui kata-kata positif, dan 2) keterampilan dalam menggunakan hypnomathematics melalui kata-kata positif.

\section{SIMPULAN}

Hasil yang dicapai melalui kegiatan pelatihan hypnomathematics melalui kata-kata positif adalah guru SD 4 Bae memperoleh pengetahuan tentang hypnomathematics melalui kata-kata positif, dan guru SD 4 Bae dapat meningkat keterampilan hypnomathematics melalui kata-kata positif.

Berdasarkan hasil yang diperoleh dalam kegiatan pengabdian masyarakat ini, beberapa saran yang bisa disampaikan adalah para guru SD agar senantiasa berupaya secara terus menerus mengembangkan kemampuan profesionalismenya melalui berbagai kegiatan pelatihan, dan penggunaan hypnomathematics melalui kata-kata positif yang telah dipraktekkan agar dilaksanakan secara berkesinambungan. 


\section{REFERENSI}

Dimyati, \& Mudjiono. (2013). Belajar dan pembelajaran. Jakarta: Rineka Cipta.

Sanjaya, W. (2009). Strategi pembelajaran berorientasi standar proses pendidikan. Jakarta: Prenada Media Group.

Sardiman, A. M. (1986). Interaksi dan motivasi belajar mengajar. Jakarta: Rajawali.

Suherman, E., Turmudi, Didi, S., Tatang, H., Suhendra, \& Sufyani, P . (2003). Strategi pembelajaran matematika kontemporer. Bandung: JICA.

Suyitno, A. (2004). Dasar-dasar dan proses pembelajaran matematika I. Semarang: FMIPA UNNES.

Tanudjaja, B. B. (2007). Pengaruh media komunikasi massa terhadap popular culture dalam kajian budaya/cultural studies. Nirmana, 9(2), 96-105.

Wati, E. R., \& Kusuma, S. (2016). Menjadi guru hebat dengan hypnoteaching. Yogyakarta: Kata Pena. 